\title{
Clinically "small" effects of air pollution on FVC have a large public health impact
}

\author{
N. Künzli*, U. Ackermann-Liebrich*, O. Brändli\#, J.M. Tschopp ${ }^{+}$, C. Schindler*, P. Leuenberger**, \\ on behalf of the Swiss Study on Air Pollution and Lung Disease in Adults (SAPALDIA) - team
}

Clinically "small" effects of air pollution on FVC have a large public health impact. $N$. Künzli, U. Ackermann-Liebrich, O. Brändli, J.M. Tschopp, C. Schindler, P. Leuenberger, on behalf of the Swiss Study on Air Pollution and Lung Disease in Adults (SAPALDIA) - team. (C) ERS Journals Ltd 2000.

ABSTRACT: Epidemiological studies have repeatedly established adverse health effects due to long-term exposure to ambient air pollution. The Swiss Study on Air Pollution and Lung Disease in Adults (SAPALDIA) published a -3.14\% decrease in forced vital capacity (FVC) per $10 \mu \mathrm{g} \cdot \mathrm{m}^{-3}$ increment in particulate matter (particles with a 50\% cut-off aerodynamic diameter of $10 \mu \mathrm{m}$ (PM10). Compared to the withinsubject variability of FVC, the effect may be considered small. This individual (or clinical) perspective is, however, misleading. The purpose of this study was to demonstrate the public health relevance of apparently "small" effects, using the impact of PM10 on FVC as an example.

The scenario compares a population A, exposed to an annual mean PM10 of 20 $\mu \mathrm{g} \cdot \mathrm{m}^{-3}$, with a population B exposed to $30 \mu \mathrm{g} \cdot \mathrm{m}^{-3}$ mean PM10.

A shift of $-3.14 \%$ in the population distribution of FVC increases the number of subjects in the lower tail of the distribution. In population $B$ a relative increase was expected of $47 \%(16-91 \%)$ in the prevalence of "FVC $<80 \%$ predicted", (i.e., from 5.17 to $7.59 \%$ and 5.88 to $8.65 \%$ among males and females, respectively). The relative increase in the prevalence of "FVC $<70 \%$ predicted" ( $~ 1 \%$ of population) was $63 \%$ (30-98\%, males) and 57\% (21-86\%, females).

An epidemiological estimate of a change in the mean value of the population distribution should not be misinterpreted as an effect on the individual level. However, the impact of a $10 \mu \mathrm{g} \cdot \mathrm{m}^{-3}$ increase in particles with a $50 \%$ cut-off aerodynamic diameter of $10 \mu \mathrm{m}$ (PM10) on the number of subjects with a clinically relevant reduction in lung function is quantitatively important.

Eur Respir J 2000; 15: 131-136.

\begin{abstract}
*Institute for Social and Preventive Medicine, University Basel, Basel, Switzerland. ${ }^{\#}$ Zürcher Höhenklinik, Wald, Switzerland. ${ }^{+}$Centre Valaisan de Pneumologie, Montana, Switzerland. **Division of Pneumology, University Hospital Lausanne, Switzerland.
\end{abstract}

Correspondence: N. Künzli, Institut für Sozial- und Präventivmedizin der Universitaät Basel, Steinengraben 49, 4051 Basel, Switzerland, Fax: 41612676190

Keywords: Air pollution

environmental health

forced vital capacity

public health

Received: November 101998

Accepted after revision August 291999

SAPALDIA, a project of the Swiss National Science Foundation, is part of the National Research Program NFP/PNR 26 (Grant 4026-028099). N. Künzli is a recipient of a National Science Foundation Advanced Scientist Feilowship (\#3233048922.96/1)
In recent years, epidemiological research has repeatedly shown that current levels of air pollution are associated with health effects $[1,2]$. There is evidence that air pollution may cause, induce, or aggravate functional changes, morbidity, and mortality with some effects being closely related to daily changes in air pollution (shortterm effects) whereas others should be considered the effects of long-term exposure [3, 4]. In general, European studies confirm the findings from the USA, both in large urban areas [5] and in rather small areas with low to moderate pollution levels $[6,7]$.

The biological mechanisms causing the health effects of air pollution have not yet been fully established. The consistency and coherence across epidemiological studies supports, however, the conclusion that the complex mixtures of air pollution deteriorate public health [8]. A widely used health relevant indicator of the air pollution mixture is particulate matter, mainly particles with a $50 \%$ cut-off aerodynamic diameter of $10 \mu \mathrm{m}$ (PM10). In fact, many studies have reported exposure-response relationships for ambient PM10.

Although the reported effects of air pollution on human health are well accepted by the majority of the scientific community, it is commonly believed that the impact is small. This interpretation stems from considering the size of the observed relative risks (RR) between populations with low air pollution exposure and those with a higher level e.g., $10-20 \mu \mathrm{g} \cdot \mathrm{m}^{-3}$ of PM10, which are usually very small, and are clearly $<2.0$ across the observed range of air pollution levels [9]. The phenomenon that small relative risks may be of large public health impact is well known among public health professionals $[10,11]$. In a clinical setting, however, the discrepancy between the individual $\mathrm{RR}$ and the population attributable risk perspective may often be ignored. It is the purpose of this article to visually and quantitatively translate the epidemiological findings into a clinically relevant context, thus demonstrating the relevance of air pollution in the field of respiratory health.

The association of ambient air pollution levels with the forced vital capacity (FVC), or with the forced expiratory volume in one second (FEV1) is one example of a "small" effect. The Swiss Study on Air Pollution and Lung Disease in Adults (SAPALDIA) study for example, published a $3.14 \%$ decrement in mean $\mathrm{FVC}$ for a $10 \mu \mathrm{g} \cdot \mathrm{m}^{-3}$ increase in the long-term levels of ambient PM10 [6]. On an individual level, a 3\% decrease in FVC is within the range of 
the biological variability between two measurements [12]. Therefore, from the individual clinical perspective, these effects are considered to be of little relevance. However, as emphasized by Rose $[10,11]$, this is a misinterpretation of epidemiological study results. The seminal work of Rose [11] extensively discussed the public health relevance of small changes in population mean values and their implications for prevention. Although Rose [11] particularly referred to cardiovascular diseases, the generalization of the issue was also emphasized. The current authors will clarify the inherent meaning of "small changes" in the population mean, using the published impact of PM10 on lung function as an illustration [6]. This can be considered a typical example in the field of environmental health where RR are usually small across the observed range of environmental exposure.

Although the exercise may be performed for both FVC and FEV1 [6], the authors will restrict the calculation to the association of air pollution with FVC. A similar presentation for FEV1 might easily mislead, giving the interpretation that long-term air pollution exposure may be a cause for asthma. As there is little evidence for such an association, the authors prefer to present the calculations for FVC.

\section{Methods}

FVC is measured on a continuous scale. The assessment of FVC is very reliable and repeated measures in one subject usually vary by $<5 \%$, which is considered to be the maximum acceptable variability for a reliable measurement of FVC [13]. To assess the impact of air pollution on FVC, epidemiological studies have to include large populations of different levels of risk factor exposure. Within large populations, FVC is almost normally distributed, after taking into account sex, age and height. Given the population distribution of FVC, some subjects will have values $<80 \%, 70 \%$ or even $60 \%$ of normal, all of which are considered to be clinically relevant impairments of pulmonary function. Depending on the level of air pollution, the population mean value of the distribution may differ [6]. In fact, it is this difference (or shift) in the population mean that has been published in SAPALDIA [6].

To demonstrate the issue, the authors have simulated the distribution of FVC values in two model populations, A and B. For both populations the prevalence of "low FVC" was calculated using three different cut-offs $(<80 \%,<70 \%$ and $<60 \%$ predicted) with the SAPALDIA "normal" values as reference values [14]. It is assumed that the only difference between these two populations is the level of ambient concentrations of PM10, as the indicator of air pollution.

For the first population (A), with a long-term PM10 mean of $20 \mu \mathrm{g} \cdot \mathrm{m}^{-3}$ the distribution properties of FVC are adopted as observed in the SAPALDIA population of the cross-sectional investigation [15]. The eight-centre study SAPALDIA assessed subjective and objective health factors, including pulmonary function, among a random population sample of adults $(n=9,651$ : age $18-60 \mathrm{yrs})$. All participants performed spirometry according to the American Thoracic Society (ATS) guidelines [13]. The predicted "normal" values of the nonsmoking population have been published previously [14]. The current authors have used FVC in per cent of the predicted value, which was close to normally distributed (fig. 1). On average, the SAPALDIA areas had ambient PM10 levels of $20 \mu \mathrm{g} \cdot \mathrm{m}^{-3}$. For the second population (B), an average PM10 exposure of $30 \mu \mathrm{g} \cdot \mathrm{m}^{-3}$ was assumed. This corresponds to the annual mean level of PM10 as observed in larger urban areas in Switzerland.

In the SAPALDIA study, it was shown that the higher the ambient level of air pollution, the lower the adjusted mean FVC is $[6,16]$. The major results of this publication are summarized in the upper part of table 1. For an increase in ambient PM10 concentrations of $10 \mu \mathrm{g} \cdot \mathrm{m}^{-3}$, FVC was $3.14 \%$ lower. Therefore, to simulate the distribution of $\mathrm{FVC}$ in this second population, the distribution of FVC per cent predicted was shifted by $3.14 \%$.

The underlying concept is visualised in figure 1 . The authors will quantify the increase of the area under the curve in the lower tail of the distribution, indicated as "Impact". Figure 2 shows the cumulative distributions of FVC per cent predicted of the two model populations.

It could be argued that the air pollution related change in the population mean FVC may be driven by subgroups of "susceptible" or "sensitive" subjects whereas FVC of the "nonsusceptible" may not be influenced by air pollution. As no markers of susceptibility are yet available the authors applied two different scenarios with assumptions about the percentage of people that might be "susceptible", i.e., the theoretical prevalence of "air pollution susceptibility", assuming no effect among the nonsusceptible. Under each scenario of susceptibility the authors derived the theoretical exposure-response slope of FVC on PM10 among those susceptible. The calculations were made under the assumption that the overall slope corresponds to the one observed in SAPALDIA [6]. In case of the existence of susceptible subgroups, the overall slope has to be considered as the weighted average across the slopes in susceptible and in nonsusceptible subgroups. Among the latter, the slope would be zero (the assumption being that

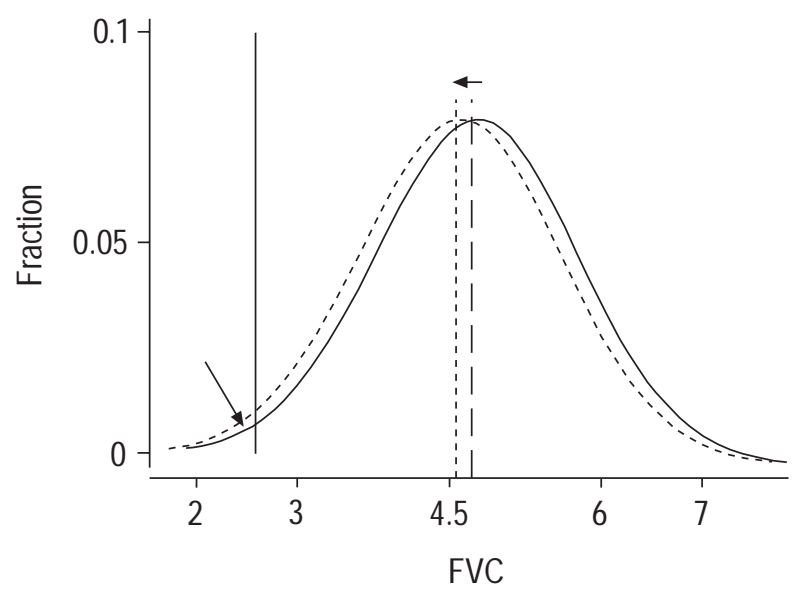

Fig. 1. - Visual presentation of a $3.14 \%$ shift of the population mean forced vital capacity (FVC) and its impact on the number of subjects with $\mathrm{FVC}<80 \%$ predicted (increase in the area under the curve in the lower tail of the distribution). The curve of population A has a mean value of $4.7 \mathrm{~L}$ and the standard deviation of $1.0 \mathrm{~L}$. — : population $\mathrm{A}$; --- : population B. The solid vertical line represents $80 \%$ of predicted FVC. The horizontal arrow indicates the shift in the population mean, and the diagonal arrow indicates the impact. 
Table 1. - Per cent change in the population mean forced vital capacity (FVC) for an increment of $10 \mu \mathrm{g} \cdot \mathrm{m}-3$ in the longterm mean air pollution concentration

\begin{tabular}{lcc}
\hline Group & $\begin{array}{c}\text { Proportion of total population } \\
\%\end{array}$ & $\begin{array}{c}\text { change in FVC per } 10 \mu \mathrm{gg} \cdot \mathrm{m}^{-3} \\
\text { PM } 10 \%\end{array}$ \\
\hline $\begin{array}{l}\text { Published results* } \\
\text { Never smoker without symptoms }\end{array}$ & 32 & -3.39 \\
Basic model & & -3.42 \\
Basic model + education & & -3.41 \\
Basic model + work exposure & & -3.54 \\
Random effects model & 44 & -3.14 \\
All never smoker & 23 & -3.03 \\
Former smoker & 33 & -3.21 \\
Current smoker & 69 & -3.16 \\
Long-term residents $\geq 10$ yrs & 100 & -3.14 \\
Total SAPALDIA population & & -6.28 \\
Calculation for "susceptible subgroups" & & -15.70 \\
assuming 50\% of population to be susceptible & \\
assuming 20\% of population to be susceptible & & \\
\hline
\end{tabular}

*: all effects were strongly significant $\left(\mathrm{p}<0.001\right.$; Ref. [6]; ${ }^{*}$ : adjusted for sex, age, height, weight, atopic status, pack-yrs (former and current smokers), and daily number of cigarettes; ${ }^{+}$: the calculated slopes are derived under the assumption that the overall slope (i.e., across susceptible and nonsusceptible subgroups) corresponds to the observed slope of the total the Swiss Study on Air Pollution and Lung Disease in Adults (SAPALDIA) population. The slope among nonsusceptible is assumed to be zero. PM10: particles with a 50\% cut-off aerodynamic diameter of $10 \mu \mathrm{m}$.

PM10 is uncorrelated with the FVC). Again, the prevalence of low FVC was derived for the respective distributions of FVC per cent predicted. The lower part of table 1 shows the calculated expected effect slopes under two different susceptibility scenarios with only $50 \%$ and $20 \%$ considered to be "susceptible to air pollution".

\section{Results}

Table 2 shows the prevalence of low FVC derived for different cut-offs to define "low FVC". The estimated prevalence of subjects with FVC $<80 \%$ predicted is expected to increase in both sexes by $47 \%$. In other words, population $\mathrm{B}$ is expected to have 76,000-87,000 subjects per million with impaired FVC as compared to 52,000-

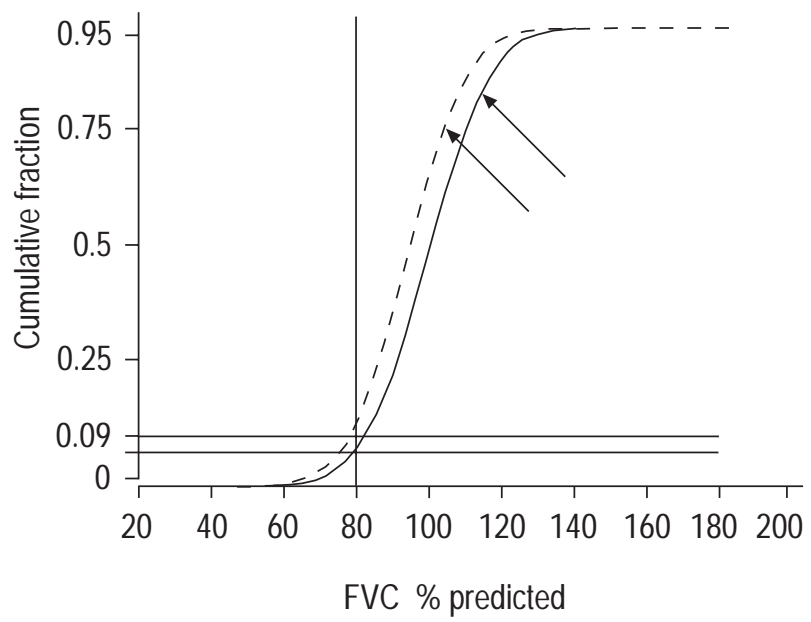

Fig. 2. - Cumulative distribution of forced vital capacity (FVC) per cent predicted in population A and population B. The vertical line indicates $80 \%$ predicted; the respective population fractions below $80 \%$ predicted are marked, population $\mathrm{A}(\sim 5 \%)$ and $\mathrm{B}(\sim 8 \%)$ on the y axis. population A (arrow indicates the annual mean particles with a $50 \%$ cutoff aerodynamic diameter of $10 \mu \mathrm{m}$ (PM10) of $20 \mu \mathrm{g} \cdot \mathrm{m}^{-3} ;-\cdots$ : population B (arrow indicates annual mean PM10 of $30 \mu \mathrm{g} \cdot \mathrm{m}^{-3}$.
59,000 per million in population $\mathrm{A}$, with the difference between the two estimates being the number of cases attributable to the higher level of air pollution. The percentage change was slightly larger for $\mathrm{FVC}<70 \%$ predicted and smaller for the lowest cut-off considered $(<60 \%$ predicted).

Table 3 shows the impact of a $10 \mu \mathrm{g} \cdot \mathrm{m}^{-3}$ change in PM10 on the prevalence of FVC $<80 \%$ predicted, assuming that only $50 \%$ and $20 \%$, respectively, would be susceptible. The smaller the proportion of susceptible, the larger the air pollution attributable for the per cent increase in the prevalence of subjects with impaired FVC. Under the rather unlikely assumption (see Discussion section) of only $20 \%$ being susceptible to air pollution, the prevalence of impaired FVC $(<80 \%$ predicted $)$ would be about twice as high in population $\mathrm{B}$.

\section{Discussion}

Epidemiological studies frequently report changes in the population mean value of continuously measured health outcomes in relation to a defined exposure. Such epidemiological results may be misinterpreted as the effect of exposure on the level of an individual or a patient. The current authors used the change of the population mean FVC for an increment of $10 \mu \mathrm{g} \cdot \mathrm{m}^{-3}$ in the long-term level of PM10 pollution to demonstrate the significance of only small shifts in the population mean. Rose [11] demonstrated this feature in a variety of clinical settings e.g., using the distributions of serum cholesterol of subjects with and without coronary heart disease $[10,11]$. The approach of the current study was to use the prevalence of subjects with impaired FVC as a clinically more relevant health outcome, which further highlights the link between the individual (clinical) and public (epidemiological) health perspective. This transition from the usually reported dose-response function to the expected prevalence of subjects with clinically relevant impairment in lung function demonstrates the relevance of epidemiological findings about the effects of "small risks" such as air pollution. 
Table 2. - Derived prevalence of forced vital capacity (FVC) $<80 \%, 70 \%$ and $<60 \%$ predicted in males and females in populations $A$ and $B$

\begin{tabular}{|c|c|c|c|c|}
\hline \multirow{2}{*}{ FVC cut-off level } & & \multicolumn{2}{|c|}{ Prevalence at annual mean PM10 of } & \multirow{2}{*}{$\begin{array}{l}\text { Air pollution related } \\
\text { change in prevalence* }\end{array}$} \\
\hline & & $20 \mu \mathrm{g} \cdot \mathrm{m}^{-3}$ & $30 \mu \mathrm{g} \cdot \mathrm{m}^{-3}$ & \\
\hline \multirow[t]{3}{*}{ Male } & $\leq 80$ & 5.17 & 7.59 & $47(16-91)$ \\
\hline & $\leq 70$ & 1.05 & 1.71 & $63(30-98)$ \\
\hline & $\leq 60$ & 0.21 & 0.23 & $11(10-44)$ \\
\hline \multirow[t]{3}{*}{ Female } & $\leq 80$ & 5.88 & 8.65 & $47(20-85)$ \\
\hline & $\leq 70$ & 1.22 & 1.91 & $57(21-86)$ \\
\hline & $\leq 60$ & 0.34 & 0.45 & $76(30-38)$ \\
\hline
\end{tabular}

Data are presented as percentages, with the FVC cut-off levels being expressed as the per cent predicted. Population A $\left(20 \mu \mathrm{g} \cdot \mathrm{m}^{-3}\right)$ corresponds to the "average Swiss Study on Air Pollution and Lung Disease in Adults (SAPALDIA) population"; population B: 30 $\mu \mathrm{g} \cdot \mathrm{m}^{-3}$. \#: assuming the same particles with a $50 \%$ cut-off aerodynamic diameter of $10 \mu \mathrm{m}$ (PM10) effect for all subjects; *: the variability indicated in parentheses is based on the use of the upper and lower air pollution effect estimate from the $95 \%$ confidence interval $(95 \% \mathrm{CI})$, random effect model with a mean effect of $3.14 \%$ (95\% CI: $1.39-5.13)$ [6].

This assessment requires the assumption of a causal association between air pollution and the change in lung function. The authors refer to the concept of causality outlined by RothмаN et al. [17] and consider air pollution as a component rather than a single sufficient cause.

The current calculation has shown that a $3.14 \%$ shift in the population mean FVC may have a rather strong impact on the prevalence of people with severely impaired FVC in the population, although the same decrement observed in an individual would seem to be very small, having no clinical relevance. The apparent discrepancy between the $\mathrm{RR}$ and the population attributable risk stems from the fact that the latter is determined not only by the RR but also by the number of people exposed, $(100 \%$ for air pollution exposure) and the prevalence of the negative health outcome, i.e., in this case, the impaired FVC $[10,18]$. To acknowledge this latter issue, the authors separately calculated the impact for males and females. Although there is no evidence for sex specific effects of air pollution, the baseline prevalence, and thus the number of attributable cases of impaired FVC may vary.

The current scenarios regarding the number of those "susceptible" or "sensitive" to air pollution injury further clarify the problem in interpreting population based results at the individual level. The observed change of FVC indicates that the "average statistical person" experiences a $3.14 \%$ lower FVC if PM10 levels are $10 \mu \mathrm{g} \cdot \mathrm{m}^{-3}$ higher. In their scenarios the authors made the extreme assumptions that only susceptible subgroups truly experience an impact of PM10 whereas among nonsusceptible people there may be no association between long-term average PM10 and FVC. Thus, the dose-response slope must be larger among those susceptible than the average overall slope, observed in the total population [6]. In the present example, the relative impact of a $10 \mu \mathrm{g} \cdot \mathrm{m}^{-3}$ change in PM10 increased, the smaller the susceptible groups were. Although the calculations of scenarios are mathematically correct, the unanswered question is whether there truly are risk groups for lung function impairment due to air pollution. This cannot be answered yet. In the SAPALDIA study, however, the adjusted associations of air pollution with FVC were rather stable across several subgroups, including groups defined by smoking status (table 1), therefore, not providing a marker to define susceptible subgroups. Stable effect estimates across subgroups are, however, compatible with the "susceptible subgroup" hypothesis if the (unknown) markers for susceptibility were equally distributed across the subgroups considered.

Table 3. - Prevalence of forced vital capacity (FVC) $<80 \%$ predicted for three susceptibility scenarios

\begin{tabular}{|c|c|c|c|c|c|}
\hline \multirow[t]{2}{*}{ Scenario assumption* } & \multicolumn{2}{|c|}{$\begin{array}{l}\text { Percentage change of FVC per } \\
10 \mu \mathrm{g} \cdot \mathrm{m}^{-3} \text { PM } 10\end{array}$} & \multicolumn{2}{|c|}{$\begin{array}{c}\text { Percentage of subjects with FVC } \leq 80 \% \\
\text { predicted at PM10 levels of: }\end{array}$} & \multirow{2}{*}{$\begin{array}{l}\text { Air pollution related } \\
\text { change in the } \\
\text { prevalence of FVC } \\
<80 \% \text { pred }\end{array}$} \\
\hline & $\begin{array}{l}\text { Among total } \\
\text { population }^{\#}\end{array}$ & $\begin{array}{l}\text { Among } \\
\text { susceptible }\end{array}$ & $20 \mu \mathrm{g} \cdot \mathrm{m}^{-3}$ & $30 \mu \mathrm{g} \cdot \mathrm{m}^{-3}$ & \\
\hline \multicolumn{6}{|l|}{ Male } \\
\hline 100 & -3.14 & -3.14 & 5.17 & 7.59 & 47 \\
\hline 50 & -3.14 & -6.28 & 5.17 & 8.13 & 57 \\
\hline 20 & -3.14 & -15.70 & 5.17 & 10.86 & 110 \\
\hline \multicolumn{6}{|l|}{ Female } \\
\hline 100 & -3.14 & -3.14 & 5.88 & 8.65 & 47 \\
\hline 50 & -3.14 & -6.28 & 5.88 & 9.18 & 56 \\
\hline 20 & -3.14 & -15.70 & 5.88 & 11.36 & 93 \\
\hline
\end{tabular}

Susceptibility scenarios assumed that 1) on average, the whole population (100\%) are susceptible, 2 ) only $50 \%$, and 3 ) only $20 \%$ of the population are susceptible. *: percentage of population being susceptible to air pollution; ${ }^{*}$ : the slope among the total population is assumed to be the overall slope observed in the Swiss Study on Air Pollution and Lung Disease in Adults (SAPALDIA) [6]. This corresponds to the weighted average of the slopes in susceptible and nonsusceptible subgroups. The slope among the nonsusceptible is assumed to be zero. Particles with a $50 \%$ cut-off aerodynamic diameter of $10 \mu \mathrm{m}$ (PM10) levels of $20 \mu \mathrm{g} \cdot \mathrm{m}^{-3}=$ population A, while levels of $30 \mu \mathrm{g} \cdot \mathrm{m}^{-3}=$ population B. 
The calculations, based on published dose-response functions for FVC, were simulations of population distributions of FVC per cent predicted. To empirically confirm the evidence for the model, the authors made a further analysis on the SAPALDIA data, using the prevalence of "FVC $<80 \%$ predicted" as the outcome measure. Based on a logistical model, adjusted for the same cofactors as in the original analyses [6], i.e., sex, atopy, height, weight, age, smoking status and amount of cigarettes smoked, the authors observed a significant positive association between the mean level of PM10 and the proportion of people with FVC $<80 \%$ predicted (not shown). For a 10 $\mu \mathrm{g} \cdot \mathrm{m}^{-3}$ increment in the long-term level of PM10, the increase in the prevalence of impaired FVC was $66 \%(95 \%$ confidence interval (CI): $46-88 \%$ ). This is similar to the simulation based estimates of $47 \%$ with a $95 \%$ CI of 20 91\% among males and females (table 2).

The postulated impact of long-term exposure to PM10 on the occurrence of low FVC may be directly assessed in cohort studies. The authors are aware of one recent presentation of the Harvard Six-Cities study [19]. In this preliminary analysis of the 12-yr cohort study, the incidence of FVC $<80 \%$ predicted was reported to increase by $31 \%$ (3-69\%) for a change of $18.6 \mu \mathrm{g} \cdot \mathrm{m}^{-3}$ in fine ambient particles (PM2.5). This may correspond approximately to a $20 \%$ increase per $10 \mu \mathrm{g} \cdot \mathrm{m}^{-3} \mathrm{PM} 10$, empirically supporting the current authors' health impact assessment scenarios.

It is emphasized that an FVC below some threshold value, e.g., $80 \%$ predicted, may neither be a strict nor the single criterion in a clinical setting. Nevertheless, cut-offs are used in the clinical process, guiding diagnostic, therapeutic or disability assessment decisions. Therefore, the estimated effect of air pollution on the prevalence of subjects with impaired FVC is expected to have a direct impact on public health services and costs.

The impact of air pollution on FVC as an objective functional measure is of particular scientific importance. Apart from the strong impact of age and smoking on lung function, both FVC and FEV1, have been repeatedly shown to be strong and independent predictors of all cause mortality $[20,21]$. As already shown in an early publication of the Framingham study [22], reduced baseline FVC was associated not only with increased respiratory mortality but with mortality due to a broad range of other causes [22]. The fact that long-term mean air pollution was found to be related to 1) pulmonary function $[6,23]$; 2 ) chronic respiratory symptoms [24]; and 3) life expectancy $[3,4]$ is not only coherent with a causal relationship between air pollution and health impact but also renders lung function measures to be an important "missing link" on the pathophysiological chain leading to air pollution related diseases [9].

From a preventive perspective, the current example highlights the importance of the "population strategy" to abate air pollution as opposed to the "high risk strategy" with focus on inherently small subgroups of the population with particularly high risks for diseases [11]. As shown by Rose [11], and corroborated by the current study, the strategy has great potential for populations, although the benefit for individuals may be small.

In conclusion, the currently suggested way of presenting the impact of air pollution on lung function at the population level rather than at the individual level of relative risks shows that a small change in the population mean of a quantitative measure can have considerable impact on the number of subjects with relevant impairment.

Team members of the SAPALDIA study. Study director: Ph. Leuenberger (p). Programme director: U. Ackermann-Liebrich (e), P. Alean (am), K. Blaser (a), G. Bolognini (p), J.P. Bongard (p), O. Brändli (p), P. Braun (p), C. Bron (l), M. Brutsche (l), C. Defila (m), G. Domenighetti (p), S. Elsasser (1), L. Grizé (s), P. Guldimann (l), P. Hufschmied (1), W. Karrer (p), H. Keller-Wossidlo (o), R. Keller (p), N. Künzli (e), J.C. Luthi (I), B.W. Martin (I), T. Medici (p), Ch. Monn (am), A.G. Peeters (pa), A.P. Perruchoud (p), A. Radaelli (1), Ch. Schindler (s), J. Schwartz (s), G. Solari (p), M. Schöni (p), J.M. Tschopp (p), B. Villiger (p), B. Wüthrich (a), J.P. Zellweger (p), E. Zemp (e). a: allergology; am: air pollution monitoring; e: epidemiology, l: local assistant MD; m: meteorology; o: occupational medicine; p: pneumology; pa: palynology; s: biostatistic.

\section{References}

1. American Thoracic Society, Committee of the environmental and occupational health assembly of the American Thoracic Society. Health effects of outdoor air pollution. State of the art. Part I. Am J Respir Crit Care Med 1996; 153: 3-50.

2. American Thoracic Society, Committee of the environmental and occupational health assembly of the American Thoracic Society. Health effects of outdoor air pollution. State of the art. Part II. Am J Respir Crit Care Med 1996; 153: 477-498.

3. Dockery D, Pope A, Xu X, et al. An association between air pollution and mortality in six U.S. Cities. $N$ Engl $J$ Med 1993; 329: 1753-1759.

4. Pope A, Thun M, Namboodiri M, et al. Particulate air pollution as a predictor of mortality in a prospective study of U.S. adults. Am J Respir Crit Care Med 1995; 151: 669-674.

5. Katsouyanni K, Schwartz J, Spix C, et al. Short term effects of air pollution on health: a European approach using epidemiologic time series data: the APHEA protocol. J Epidemiol Commun Health 1996; 50 (Suppl. 1): S12-S18.

6. Ackermann-Liebrich U, Leuenberger P, Schwark J, et al. Lung function and long-term exposure to air pollutants in Swikerland. Am J Respir Crit Care Med 1997; 155: 122129.

7. Braun-Fahrländer C, Vuilie J, Sennhauser F, et al. Respiratory Health and long-term exposure to air pollutants in Swiss schoolchildren. Am J Respir Crit Care Med 1997; 155: 1042-1049.

8. Bates D. Health indices of the adverse effects of air pollution: the question of coherence. Environ Res 1992; 59: 336-349.

9. Wilson RSJe. Particles in our air. Concentrations and health effects. Harvard School of Public Health. Boston, USA, Harvard university Press, 1996.

10. Rose G. Sick individuals and sick populations. Int J Epidemiol 1985; 14: 32-38.

11. Rose G. The strategy of preventive medicine. New York, USA, Oxford Medical Publications, 1992.

12. American Thoracic Society. Standardization of spirometry. Update 1994. Am J Respir Crit Care Med 1995; 152: $1107-1136$. 
13. American Thoracic Society. Standardization of spirometry - 1987 update. Am Rev Respir Dis 1987; 136: 12851298.

14. Brändli O, Schindler C, Künzli N, Keller R, Perruchoud A, SAPALDIA Team. Lung function in healthy never smoking adults. Reference values and lower limits of normal of a Swiss population. Thorax 1996; 51: 277283.

15. Martin B, Ackermann-Liebrich U, Leuenberger $\mathrm{P}$, et al. SAPALDIA - methods and participation in the crosssectional part of the Swiss study on air pollution and Lung Disease in Adults. Soz Prðventivmed 1997; 42: 67-84.

16. Schindler C, Ackermann-Liebrich U, Leuenberger P, et al. Associations between lung function and estimated average exposure to $\mathrm{NO}_{2}$ in 8 areas of Switzerland (SAPALDIA). Epidemiology 1998; 9: 405-411.

17. Rothman KJ, Greenland S. Modern Epidemiology. 2nd Edn. Philadelphia, PA, USA, Lippincott-Raven Publishers, 1998.

18. Northridge ME. Public health methods - attributable risk as a link between causality and public health action. $\mathrm{Am} J$ Public Health 1995; 85: 1202-1203.
19. Neas L, Hoek G, Dockery D. Air pollution and the incidence of adult pulmonary function deficits in six US cities. Epidemiology 1998; 9: S160.

20. Sorlie P, Kannel W, O'Connor G. Mortality associated with respiratory function and symptoms in advanced age; the Framingham study. Am Rev Respir Dis 1989; 140: 379-384.

21. Neas LM, Schwartz J. Pulmonary function levels as predictors of mortality in a national sample of US adults. Am J Epidemiol 1998; 147: 1011-1018.

22. Ashley F, Kannel W, Sorlie P, Masson R. Pulmonary function: relation to aging, cigarette habit, and mortality; the Framingham study. Ann Internal Med 1975; 82: 739745 .

23. Abbey D, Burchette R, Knutsen S, McDonnel W, Lebowik M, Enright P. Long-term particulate and other pollutants and lung function in nonsmokers. Am J Respir Crit Care Med 1998; 158: 289-298.

24. Zemp E, Elsasser S, Schindler C, et al. Long-term ambient air pollution and chronic respiratory symptoms (SAPALDIA). Am J Respir Crit Care Med 1999; 159: 1257-1266. 